\title{
GEOLOGIE VAN DIE ADDO-OLIFANT NASIONALE PARK*
}

\author{
deur
}

\author{
D. K. TOERIEN**
}

\begin{abstract}
Samevatting - Geologiese aspekte van die Addo-olifant Nasionale Park word beskryf. Die topografie, fisiografie en geologie word behandel, asook 'n aanduiding van fossiele (hoofsaaklik Mollusca) wat aangetref word.

Abstract - Geological aspects of the Addo Elephant National Park are described. The topography, physiography and geology is discussed, including a brief survey of fossils (mainly Mollusca) encountered.
\end{abstract}

\section{Inleiding}

Die Addo-olifant Nasionale Park lê sowat $72 \mathrm{~km}$ noord en is maklik bereikbaar vanaf die hawestad Port Elizabeth (Figuur 1). Dit beslaan ongeveer 7446 ha digbeboste laagland en heuwels net noord van die Sondagsriviervallei naby Addo, en word aan die noorde- en westekant begrens deur die Port Elizabeth-Cradockspoorlyn,

Hoewel verspreid oor die jaar, is die reënval die hoogste gedurende die somermaande en met uitsondering van droë seisoene soos dié van 1969-70, in die omgewing van $500 \mathrm{~mm}$ per jaar.

Die plantegroei is die spekboom (Portulacaria afra) en harde doringrige tipe bosse wat so dig groei dat gemaakte- en wildvoetpaaie die enigste deurgang bied in die grootste gedeelte van die park. Alleen in die heuwelagtige oostelike en suidoostelike dele waar sandgrond voorkom, bereik sommige van die yler bosse boomhoogte en groei die gras welig. Andersins is natuurlike bome afwesig.

\section{Topografie}

'n Heuwelagtige laagland wat Algoabaai begrens, dring tot oor $70 \mathrm{~km}$ die binneland in tussen die oossuidoosstrekkende Groot Winterhoekbergreeks en die Suurberg. Hierop is die olifantpark geleë sowat $7 \mathrm{~km}$ suid van die Suurberg.

Die Sondagsrivier wat grootliks bygedra het tot die verkerwing van die

*Gepubliseer ingevolge die Staatsdrukker se outeursregvergunning 4597 van 27.10 .71

**Geologiese Opname, Department van Mynwese, Nuwe Museumgebou, Visagiestraat, Pretoria. 


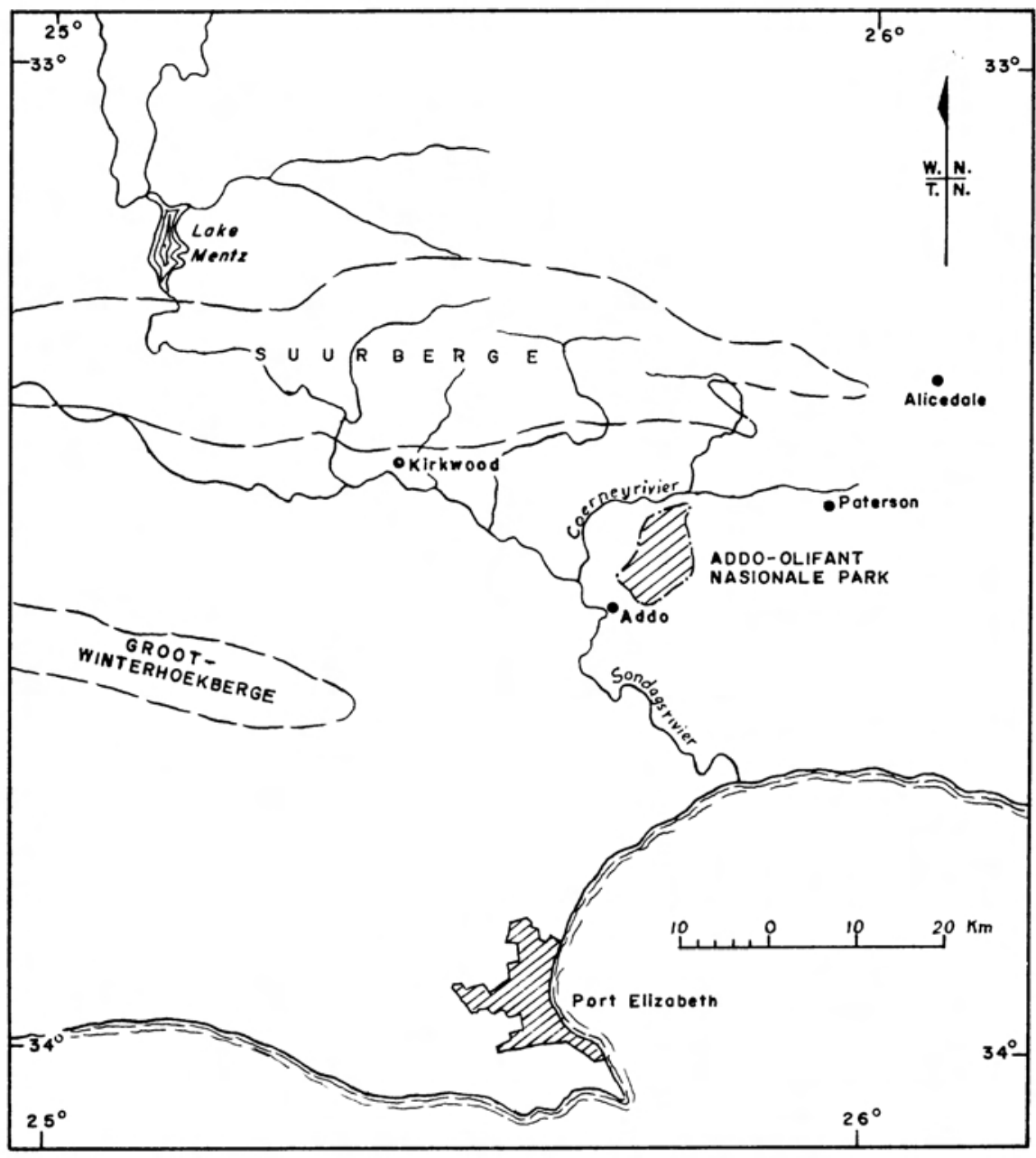

Fig.I Lokaliteitskaart van Addo-Olifant Nasionale Park Locality map of Addo Eliphant National Park

laagland vloei suidooswaarts suid van die park verby, en 'n klein sytak hiervan, die Coerneyrivier, dreineer die gebied onmiddellik noord daarvan.

In die sentraal-oostelike hoek van die park lê 'n smal oorblyfsel van 'n platogedeelte wat uitstyg tot 'n hoogte van net oor $300 \mathrm{~m}$ bo seevlak. Dit strek eers suidweswaarts vanaf die $315 \mathrm{~m}$ hoë trigonometriese baken Suurkop, swaai dan suidoos verby die $341 \mathrm{~m}$ hoë baken Kenmure, en strek dan ooswaarts voort buite die grens van die park.

Vanaf die plato daal die oppervlakte aanvanklik redelik skerp in die vorm van 'n klein eskarp na die noorde, weste en suide, m.a.w. plat vinnig af sodat die res van die park in hoogte wissel tussen 75 en $125 \mathrm{~m}$ bo seevlak. 

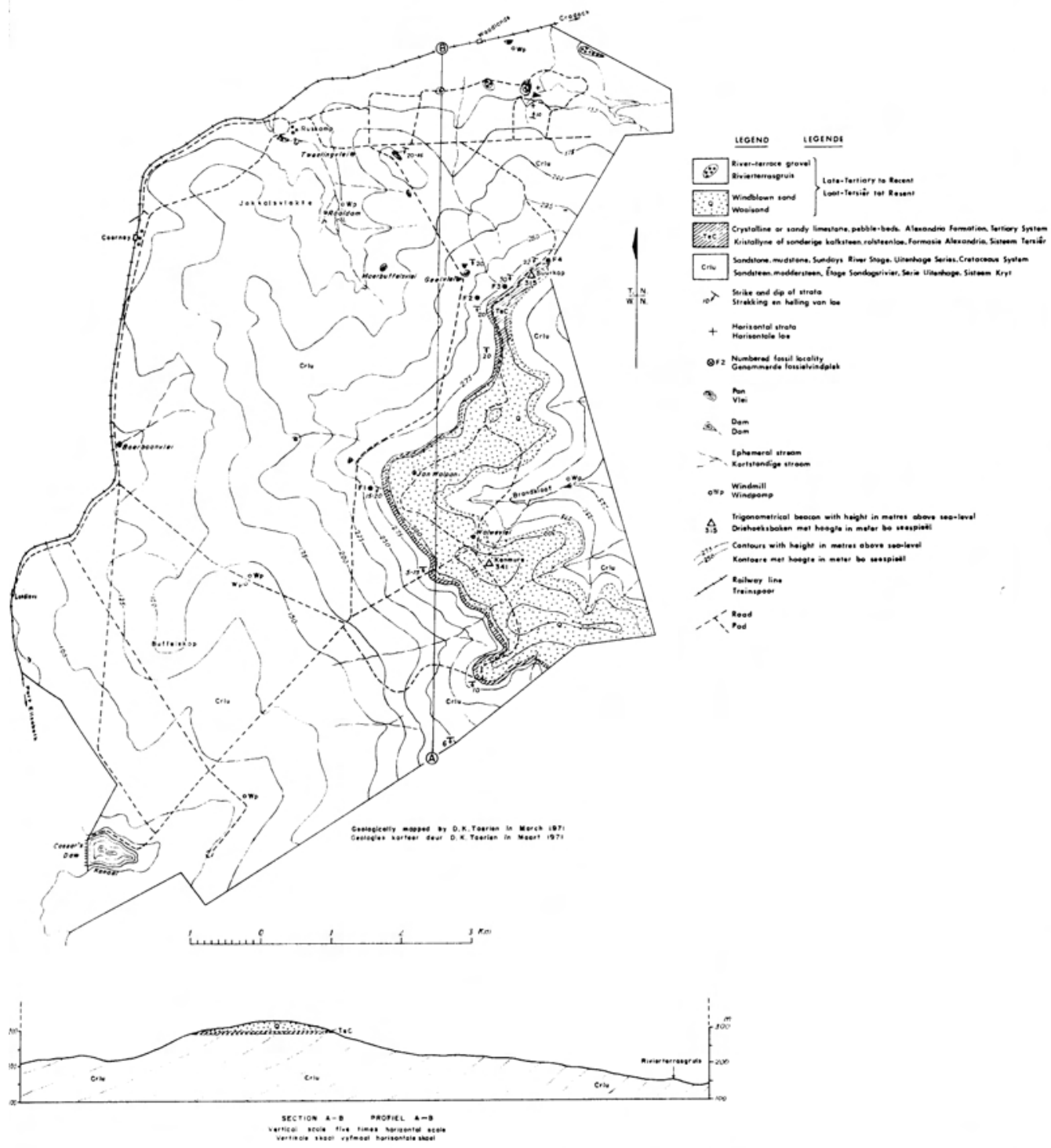
$\mathrm{Na}$ die ooste is die daling ook redelik skerp tot by die nabygeleë oosgrens.

'n Paar droë spoelslote kom voor teen die hange van die platotjie maar die verdwyn spoedig in vlak wye valleitjies wat na die noorde en suide dreineer. 'n Paar pannetjies lê verstrooi oor die park. Die Caeser's dam in die suidwestelike hoek van die park waar 'n seekoei woon, is in werklikheid 'n besproeiingsdam vir gronde in die Sondagsriviervallei.

\section{Fisiografie}

In die Kryttydperk, ongeveer 70 tot 135 miljoen jaar gelede, is die suiden ooskus van Suid-Afrika vanaf'n baie laer hoogte as die huidige seevlak, met tussenposes tot honderde meters daarbo geleidelik deur die see oorstroom. In die Gamtoosrivier- en Sondagsriviervallei-gebiede is die sedimente wat as die Serie Uitenhage bekend staan, toe neergelê. Dit is hierdie sedimente wat nou in verkerfde vorm die grootste gedeelte van die park se oppervlakte beslaan (sien meegaande geologiese kaart).

Die land het hierna weer gestyg relatief tot seevlak en die sedimente is blootgelê aan verwering, om maar weer gevolg te word deur nog 'n oorstroming deur die see in die Tersiêre tydperk tussen 70 en 2 miljoen jaar gelede. 'n Landwaartsstygende, relatief gelyk vloer of branderstoep is toe oor die Krytsedimente geskuur. Op hierdie vloer, by Suurkop byna $300 \mathrm{~m}$ bo seevlak, lê die relatief dun Tersiêre sedimente bekend as die Alexandrialae.

By herhaling het die land weer gestyg; die see het ver teruggetrek en riviere het die blootgelegde kusvlakte met Tersiêre en onderliggende Krytsedimente verkerf tot die huidige topografie. Oorblyfsels van die Tersiêre skuurvlak met of sonder oorliggende sedimente lê wydverspreid in hierdie geweste. So byvoorbeeld is die gewese hoë Tersiêre kuslyn vandag nog duidelik waarneembaar noord teen die Suurberg vanaf Suurkop. Dit vorm afgebroke terrasoorblyfsels teen die berg op 'n hoogte van ongeveer $480 \mathrm{~m}$ bo seevlak.

Waaisand in die vorm van golwende heuwels begroei met bos en gras bedek grotendeels, soos ook op bogemelde platotjie in die park, die Tersiêre afsettings. Dit verbloem sodoende die werklike oppervlakte van die Tersiêr.

Die daling van die see relatief tot die land in die Tersiêr was nie egalig nie, maar met rukke en stote, en is selfs afgewissel met stygings. Die gevolg was dat riviere wat met verposings vlaktes geskuur het, weer met verdere daling van seevlak in hierdie vlaktes ingekerf, en dan spoelgruisbedekte, afgebroke terrasse nagelaat het.

Drie sulke terrashoogtes wat heelwaarskynlik verteenwoordiging ook buite het, het in die park bewaar gebly. Die hoogste lê by Geelvlei op ongeveer $247 \mathrm{~m}$ bo seevlak, 'n tweede net oos van Tweelingvlei op ongeveer $216 \mathrm{~m}$, en die derde in die vorm van vier los lappies in die noordooste tussen 154 en $160 \mathrm{~m}$. 


\section{Geologie}

\section{A. Algemeen}

Die sandsteen en kwartsiet wat die nabygeleë Groot-Winterhoekberge en Suurberg bou, behoort tot die Serieë Tafelberg en Witteberg van die Kaapsisteem wat tussen 350 en 500 miljoen jaar oud is. Hulle is deel van die plooibergreekse wat Suid-Afrika in die suide omsoom. Hierdie formasies word nie in die park verteenwoordig nie.

Die volgende tabel rangskik die formasies van die Krytsisteem sowel as die jongere afsettings wat in die park voorkom vanaf die oudste tot die jongste, van onder na bo.

Laat Tersiêr tot Resent

Sisteem Tersiêr

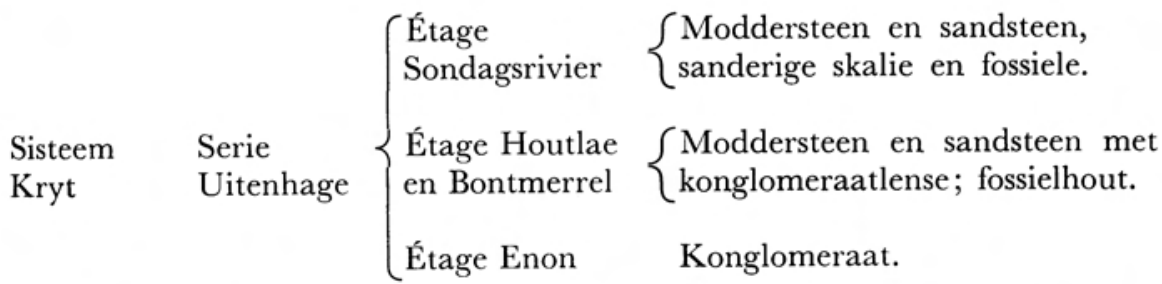

$\left\{\begin{array}{l}\text { Rivierterrasgruis, oppervlakkalk } \\ \text { en waaisand. }\end{array}\right.$ Kristallyne of sanderige kalk\{teen en rolsteenlae.

$\left\{\begin{array}{l}\text { Formasie } \\ \text { Alexandria }\end{array}\right.$$$
\text { Theen en rolsteenlae. }
$$

Die Krytsedimente in hierdie gebied staan bekend as die Serie Uitenhage. Dit het oorspronklik 'n reuse dikte gehad. 'n Boorgat deur Soekor geboor net suid van die park by Addo het 'n dikte van $3688 \mathrm{~m}$ deurgegaan. Die Serie word opgedeel in die drie Etages Enon, Houtlae in Bontmerrel, en Sondagsrivier. Die eerste twee is hoofsaaklik landelike afsettings en dagsoom gladnie in die park nie.

\section{B. Die Etage Sondagsrivier}

Die Sondagsrivierlae is van marine oorsprong. Soos op die geologiese kaart aangedui beslaan dit byna die hele parkgebied.

As gevolg van 'n algemene bedekking van rooibruin grond is dagsome van die sedimente skaars. Dit word alleen in gruisgroewe of geskraapte damme gevind en in smal slote wat hier en daar teen die platotjie hierbo genoem, gespoel is.

Die gesteentes is ' $n$ opeenvolging van afwisselende donkergroen tot grys en donkergrys moddersteen met tussengelaagde, ondergeskikte en hoofsaaklik groengrys tot roomkleurige, onsuiwer sandsteenbande.

Die moddersteenbande is meer as vyf meter dik en verweer tot helderkleurige kleie. Die sandsteenbande is somtyds ysterryk en dan donkerbruin; kalkhoudende eenhede word ook aangetref asook massiewe lae met laagvlakke tot $0,3 \mathrm{~m}$ vanmekaar. Die dikte van 'n enkele laag is selde meer as twee meter en die indruk is gekry dat hulle lensagtig in voortstrekking is.

Die kleie met rondlêende stukke sandsteen word dikwels op verweerde 
kaal kolle en by damme verspreid oor die park aangetref. 'n Tipiese voorbeeld is die dam agter die besoekershutte in die ruskamp.

Goed blootgestelde seksies van opeenvolgende lae is skaars. 'n Kort een is gemeet teen die kransie by die dam wat min of meer sentraal geleë is in die noordwestelike deel van die park. Die lae is horisontaal en as volg:

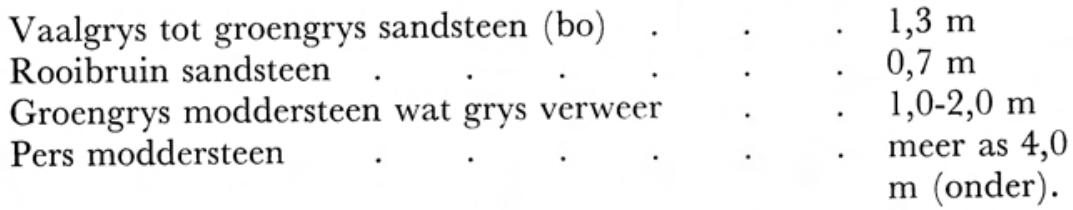

Die sandsteen is kalkryk en in 'n handmonster kan die blink oppervlaktes van kalsietkristalle duidelik gesien word.

In die bopunt van die kort sloot wat hierdie dam voed, word 'n ongeveer drie meter dik, groengrys sandsteen opgevolg deur pienk en liggrys tot geel verweerde moddersteenlae van tenminste sewe meter dik aangetref. Trosvormige donkerbruin konkresies tot $25 \mathrm{~cm}$ in deursnee en korrels tot $10 \mathrm{~cm}$ in deursnee lê uitverweer, vermoedelik afkomstig uit die sandsteen.

Grintsteen wat oorgaan tot rolsteenkonglomeraat is blootgelê in 'n vlak groef aan die noordekant van die 216 m-terras naby Tweelingvlei. Ligbruin tot geel sandsteenlae is die draers. Die sandsteenbande bevat ook skulpskerwe, is tot $115 \mathrm{~m}$ dik en hellings so hoog as $45^{\circ}$ is gemeet. Ongelukkig is die dagsoom nie duidelik blootgestel nie.

Behalwe vir horisontale ligging in die noordoostelike hoek van die park en lokale afwykings is die algemene helling van die Sondagsrivierlae van $20^{\circ}$ tot $30^{\circ}$ suid in die noorde met 'n afname tot $10^{\circ}$ en laer in die suide. Hellings is tot 'n groot mate versteur deur afbuiging as gevolg van verwering om die rand van die platotjie. Afname in helling van noord na suid na die dieper deel van die oorspronklike afsettingskom is normaal.

Oos-wesstrekkende nate wat oor $80^{\circ}$ suidwaarts hel sowel as klein verskuiwings met dieselfde strekking en afsakkant na die suide, is ook wat verwag kan word met lading in 'n afsettingskom. Sulke nate en 'n verskuiwing met ten minste drie meter verplasing is blootgelê in die aanloop tot die dam reeds gemeld.

Die Sondagsrivierlae is oor die algemeen ryk aan fossiele van ongewerwelde diere, hoofsaaklik Mollusca. Die lamellibrangiaatgenera Trigonia en Exogyra word wydverspreid aangetref. 'n Volledige opgaaf van fossiele in hierdie formasie gevind, word aangegee in 'n publikasie van die Geologiese Opname van die Republiek van Suid-Afrika: „Die Geologie van die Gebied tussen Port Elizabeth en Alexandria, Kaapprovinsie", gepubliseer in 1962. Die skrywers van hierdie publikasie (Engelbrecht, Coertze en Snyman) het in 1953 by vindplek F1 (sien meegaande geologiese kaart) die volgende Lamellibranchiata gevind: Astarte herzogi, Trigonia conocardiiformis, Modiola baini, Trigonia herzogi, Trigonia rogersi, Trigonia stowi en Trigonia vau. Hul kom voor in twee $0,5 \mathrm{~m}$ dik groengrys sandsteenbande sowat ses meter vanmekaar en ongeveer $30 \mathrm{~m}$ onderkant 
die basis van die Alexandrialae. Waar die trigonias tot $6 \mathrm{~cm}$ lank is, is die ander tipes heelwat kleiner.

Daar is meer plekke gevind waar fossiele van Mollusca voorkom. By vindplek F2 waar ook sandsteeneenhede tussengelaag met helderkleurige kleie dagsoom, word die fossiele gedra in 'n $10 \mathrm{~cm}$ dik ysteroksiedryke lagie. Hulle is tot drie centimeter lank en sluit onder ander in Ostrea en Gervillia. Hierdie is egter baie swak bewaar.

By vindplek F3 is talle goeie monsters van Trigonia herzogi en Trigonia conocardiiformis gehaal uit 'n sandsteen ongeveer 10 tot $15 \mathrm{~m}$ onderkant die basis van die Alexandrialae. Klein voorbeelde van Mytilus, Pleuromya en Pecten is ook onder die gebreekte monsters gevind.

Waar die pad vanaf die noorde teen Suurkop uitklim by vindplek F4 lê die fossiele naby die basis van die Alexandrialae aan die bokant van die pad. Net onderkant 'n $0,5 \mathrm{~m}$ dik sandsteen lê 'n 0,3 tot $0,4 \mathrm{~m}$ dik grys kleiige laag met 'n hoë inhoud van skulpskerwe. 'n Bietjie laer lê 'n 8 tot $10 \mathrm{~cm}$ dik pienk, kalkryke sandsteen met 'n dun ysteroksiedryke bandjie wat Trigonia spp. dra.

Klein stukkies fossielhout is ook opgetel by vindplek F2 en in die reedsgenoemde sloot wat die dam in die noordoostelike hoek van die park voed.

\section{Die Formasie Alexandria}

Die Alexandrialae lê op die Tersiêre terras van ongeveer $300 \mathrm{~m}$ wat reeds beskryf is. Dit is blootgelê by die baken Suurkop en dagsoom dan verder in die vorm van 'n afgebroke kransie al om die westelike rand van die plato totdat dit buite die gebied voortstrek suidwes van die baken Kenmure. Op die grootste gedeelte van die plato self en om die oostelike rand is dit bedek deur waaisand.

Regionaal hel hierdie lae vlak kuswaarts maar in die klein gebied van die park lê dit byna horisontaal met 'n duidelike diskordansievlak op die ouer Sondagsrivierlae. Die basale gedeelte is gewoonlik konglomeraties hoewel die rolstene op baie plekke yl voorkom. Dié lê tot sowat $1,5 \mathrm{~m}$ bokant die basis. Die matriks is gewoonlik kalksteen of kalkryke sand. Skulpflenters is volop en duidelik herkenbaar, en naby vindplek F2 is 'n feitlik skoon 0,7 m dik skulplaag van Ostrea-flenters. Hier is geen rekristallisasie na kalksteen nie. Die konglomeraat word min gesien daar dit bedek word deur die oorliggende kalksteen of oppervlakkalk wat verweer en teen die hange afgly. Rolstene lê egter oral ver teen die hange af versprei.

Die rolstene is byna almal goedafgeronde, wit tot vuilwit kwartsiet vanuit die Kaapsisteem afkomstig, dog hier en daar is een uit sandsteen van die Sondagsrivierlae. Die deursnee van die rolstene oorskry selde $10 \mathrm{~cm}$.

Op die konglomeraat, of selfs as matriks daarvan soos reeds gesê, volg vaalwit tot roomkleurige tot geelbruin skulpkalksteen, kalkgrond, kalkryke sand en sandsteen. Op die verweerde oppervlak is die kalksteen vuilwit tot 'n dowwe donkergrys. Dit mag gelaag of ongelaag wees met hier en 
daar 'n rolsteen. Skulpflenters is gewoonlik nog goed herkenbaar as skulp, en baie bruinomsoomde holtes waar skulpies opgelos is kom voor. Die grootte hiervan is van 3 tot $30 \mathrm{~mm}$. Die klipmure om die besoekershutte en die museum, sowel as die rotstuine in die ruskamp bevat die mooiste vars monsters van hierdie kalksteen.

Die skulpfossiele is nie maklik uit te ken nie daar dit merendeel as flenters voorkom. Dié wat reeds uitgeken is op ander plekke, is hoofsaaklik lamellibrangiate, gastropodes en oesters. 'n Volledige lys word ook in die reeds genoemde publikasie van die Geologiese Opname aangegee.

Kalksteen wissel op plekke af met sandsteen of selfs swakgekonsolideerde sanderige kalk. Die padsnit net onderkant Suurkop toon van die basis af opwaarts die volgende:

Fynkorrelrige, kalkryke, ongelaagde sand, groenerig op die basis maar ligvaal hoër op (bo) . . . $\quad 2,0 \mathrm{~m}$

Dungelaagde, kruisgelaagde, fyn kalkryke sandsteen met 3 tot $10 \mathrm{~cm}$ dik tussengelaagde kalksteenlagies . 1,4 m Goedgekristalliseerde skulpkalksteen . . . $1,0 \mathrm{~m}$ Afwisselende kalksand en skulpkalksteen (onder), net meer as . . . . . . . $4,0 \mathrm{~m}$

Die dikte van die Alexandrialae is moeilik te bepaal. Skulpflenters kan duidelik uitgeken word tot 'n hoogte van sowat $12 \mathrm{~m}$ vanaf die basis. Die res is dan moontlik oppervlakkalksteen. Die baken Suurkop staan hierop sowat $21 \mathrm{~m}$ bokant die basis van die Alexandrialae.

\section{Laat-Tersiêr tot Resente Afsettings}

\section{Waaisand}

Rooibruin waaisand bedek die grootste gedeelte van die plato in die park en sak ook af tot laag oor die Sondagsrivierlae aan die oostekant hiervan. Dit is waarskynlik duinsand wat opgewaai is met die terugtrekking van die see na die afsetting van die Alexandrialae. Op hierdie sand groei die gras welig en die bosse bereik boomhoogte.

\section{Rivierterrasgruis}

Riviergruis bedek die terrasoorblyfsels wat in die park voorkom en reeds beskryf is.

Op die 247 m-terras lê 'n dun gruislaag kol-kol bo-op oppervlakkalksteen wat die Krytsedimente bedek. Die rolstene is van 3 tot $10 \mathrm{~cm}$ in deursnee, is goed afgerond, en bestaan uit wit, liggrys en rooibruin kwartsiet.

Die $216 \mathrm{~m}$-terras dra 'n gruislaag 50 tot $70 \mathrm{~cm}$ dik met hoofsaaklik wit kwartsietrolstene, goed afgerond en ook van 3 tot $10 \mathrm{~cm}$ in deursnee.

Op die terrasoorblyfsels van 154 tot $160 \mathrm{~m}$ hoogte is die rolstene swak tot goed afgerond, van klein tot meer as $25 \mathrm{~cm}$ in deursnee, en bestaan oorwegend uit kwartsiet. Groengrys rolstene word ook gevind. Heelwat oppervlakkalk kom saam voor as bindstof. 


\section{BIBLIOGRAFIE}

Die volgende publikasies kan vir bykomstige inligting nageslaan word:

DU TOIT, A.L. 1954. Geology of South Africa. Edinburgh: Oliver and Boyd.

ENGELBRECHT, L. N. J., F. J. COERTZE en A. A. SNYMAN. 1962. Die geologie van die gebied tussen Port Elizabeth en Alexandria, Kaapprovinsie. Toel. Blaaie 3325D, 3326C en 3425B, Geol. Opn. Rep. S. Afr.

HAUGHTON, S. H. 1928. The geology of the country between Grahamstown and Port Elizabeth. Expl. Cape Sheet 9, Geol. Surv. S. Afr.

HAUGHTON, S. H. 1925. The Tertiary deposits of the south-eastern districts of the Cape Province. Trans. geol. Soc. S. Afr., 28: 27-32.

KITCHIN, F. L. 1908. The invertebrate fauna and palaeontological relations of the Uitenhage Series. Ann. S. Afr. Mus., 7 (2): 21-250.

KRIGE, A. V. 1926. An examination of the Tertiary and Quarternary changes of sea-level in South Africa, with special stress on the evidence in favour of a world-wide sinking of ocean-level. Ann. Univ. Stellenbosch, 5 (A, 1): $1-81$.

RUDDOCK, A. 1947. Terraces in the lower part of the Sundays River valley, Cape Province. Trans. roy. Soc. S. Afr., 31(4): 347-370.

RUDDOCK, A. 1968. Cainozoic sea-levels and diastrophism in a region bordering Algoa Bay. Trans. geol. Soc. S. Afr., 71 (3) : 209-233. 